\title{
6-Gingerol alleviates exaggerated vasoconstriction in diabetic rat aorta through direct vasodilation and nitric oxide generation
}

This article was published in the following Dove Press journal:

Drug Design, Development and Therapy

9 November 2015

Number of times this article has been viewed

\author{
Salah A Ghareib' \\ Hany M El-Bassossy ${ }^{1,2}$ \\ Ahmed A Elberry 3,4 \\ Ahmad Azhar ${ }^{5}$ \\ Malcolm L Watson ${ }^{6}$ \\ Zainy Mohammed Banjar \\ 'Department of Pharmacology and \\ Toxicology, Faculty of Pharmacy, \\ King Abdulaziz University, Jeddah, \\ Saudi Arabia; ${ }^{2}$ Department of \\ Pharmacology, Faculty of Pharmacy, \\ Zagazig University, Zagazig, Egypt; \\ ${ }^{3}$ Department of Clinical Pharmacy, \\ Faculty of Pharmacy, King Abdulaziz \\ University, Jeddah, Saudi Arabia; \\ ${ }^{4}$ Department of Pharmacology, Faculty \\ of Medicine, Beni Suef University, Beni \\ Suef, Egypt; ${ }^{5}$ Department of Pediatric \\ Cardiology, Faculty of Medicine, King \\ Abdulaziz University, Jeddah, Saudi \\ Arabia; ${ }^{6}$ Department of Pharmacy \\ and Pharmacology, University of Bath, \\ Bath, UK; ' ${ }^{7}$ Department of Clinical \\ Biochemistry, Faculty of Medicine, \\ King Abdulaziz University, Jeddah, \\ Saudi Arabia
}

\begin{abstract}
The aim of the present study is to investigate the effect and potential mechanism of action of 6-gingerol on alterations of vascular reactivity in the isolated aorta from diabetic rats. Male Wistar rats were divided into two experimental groups, control and diabetics. Diabetes was induced by a single intraperitoneal injection of streptozotocin $\left(50 \mathrm{mg} \mathrm{kg}^{-1}\right)$, and the rats were left for 10 weeks to develop vascular complications. The effect of in vitro incubation with 6-gingerol $(0.3-3 \mu \mathrm{M})$ on the vasoconstrictor response of the isolated diabetic aortae to phenylephrine and the vasodilator response to acetylcholine was examined. Effect of 6-gingerol was also examined on aortae incubated with methylglyoxal as an advanced glycation end product (AGE). To investigate the mechanism of action of 6-gingerol, the nitric oxide synthase inhibitor N $\omega$-nitroL-arginine methyl ester hydrochloride $(100 \mu \mathrm{M})$, guanylate cyclase inhibitor methylene blue $(5 \mu \mathrm{M})$, calcium-activated potassium channel blocker tetraethylammonium chloride $(10 \mathrm{mM})$, and cyclooxygenase inhibitor indomethacin $(5 \mu \mathrm{M})$ were added 30 minutes before assessing the direct vasorelaxant effect of 6-gingerol. Moreover, in vitro effects of 6-gingerol on NO release and the effect of 6-gingerol on AGE production were examined. Results showed that incubation of aortae with 6-gingerol $(0.3-10 \mu \mathrm{M})$ alleviated the exaggerated vasoconstriction of diabetic aortae to phenylephrine in a concentration-dependent manner with no significant effect on the impaired relaxatory response to acetylcholine. Similar results were seen in the aortae exposed to methylglyoxal. In addition, 6-gingerol induced a direct vasodilation effect that was significantly inhibited by N $\omega$-nitro-L-arginine methyl ester hydrochloride and methylene blue. Furthermore, 6-gingerol stimulated aortic NO generation but had no effect on AGE formation. In conclusion, 6-gingerol ameliorates enhanced vascular contraction in diabetic aortae, which may be partially attributed to its ability to increase the production of NO and stimulation of cyclic guanosine monophosphate.
\end{abstract}

Keywords: diabetes, 6-gingerol, vasorelaxant, nitric oxide, advanced glycation end products, vascular complications

\section{Introduction}

Diabetes mellitus (DM) is a common disease that affects almost 387 million people worldwide with a prevalence of $8.3 \%$ and an expected 205 million increase by 2035 , according to the International Diabetes Federation. ${ }^{1}$ Despite significant improvements in controlling diabetes, vascular complications remain a major cause of morbidity and mortality in patients with DM. ${ }^{2}$ Macrovascular complications of DM include coronary artery disease, ${ }^{3}$ heart failure, ${ }^{4}$ and stroke. ${ }^{5}$ In addition, microvascular diseases of DM, including nephropathy ${ }^{6}$ and retinopathy, ${ }^{7}$ continue to cause morbidity and mortality. These vascular complications may be partially attributed to impairment of vasomotor function of smooth muscles. ${ }^{8,9}$
Correspondence: Ahmed A Elberry Department of Clinical Pharmacy, Faculty of Pharmacy, King Abdul-Aziz University, University Street, Jeddah 21589, Saudi Arabia

Tel +966543430919

Fax +966 I2 695 I696

Email berry_ahmed@yahoo.com 
Ginger rhizome (Zingiber officinale), commonly known as ginger, is utilized worldwide as a spice and a flavoring agent, with a long history of medicinal use for diseases, including arthritis, pain, sore throat, constipation, indigestion, vomiting, dementia, fever, infectious diseases, and helminthiasis. ${ }^{10}$ Moreover, it is used in South Asia as a traditional medicine to treat cardiopathy and hypertension due to its vasodilator effect. ${ }^{11}$ Phytochemical reports showed that the main constituents of ginger are the gingerols, shogaols, zingerone, and paradol. ${ }^{12} 6$-Gingerol, one of the major elements of ginger, has been found to exhibit antiinflammatory, ${ }^{13}$ antihyperglycemic, ${ }^{14}$ antiangiogenic,,${ }^{15}$ and anticancer ${ }^{16}$ effects. In addition, antiplatelet aggregatory and vasorelaxatory effects of the constituents of ginger were reported by Liao et al. ${ }^{17}$ Hence, the current study is designed to investigate the effect and potential mechanism of action of 6-gingerol on alterations of vascular reactivity in the isolated aorta from diabetic rats.

\section{Materials and methods Drugs and chemicals}

6-Gingerol, N $\omega$-nitro-L-arginine methyl ester hydrochloride (L-NAME), methylene blue (MB), tetraethylammonium chloride (TEA), indomethacin (INDO), aminoguanidine (AG), ribose, bovine serum albumin (BSA), acetylcholine (ACh), and phenylephrine (PE) were purchased from Sigma-Aldrich

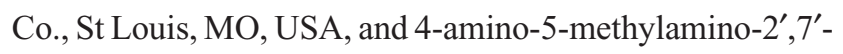
difluorofluorescein (DAF-FM) diacetate was purchased from Molecular Probes, NY, USA. All chemicals were dissolved in ultrapure deionized water except for 6-gingerol, DAF-FM diacetate, and INDO, which were dissolved in dimethyl sulfoxide (DMSO). The final DMSO concentration did not exceed $0.1 \%$ that has no effect on vascular reactivity according to our preliminary studies.

\section{Animals}

Male Wistar rats (King Abdulaziz University, Saudi Arabia) weighing 120-140 g, aged 6 weeks, were housed in clear polypropylene cages (three to four rats per cage) and kept under constant environmental conditions with equal lightdark cycle. The rats had free access to commercially available rodent pellet diet and purified water. All the experimental procedures were performed in accordance with Saudi Arabia Research Bioethics and Regulations, which are consistent with the Guide for the Care and Use of Laboratory Animals published by the US National Institutes of Health. The experimental protocol was approved by the Unit of Biomedical Ethics Research Committee, King Abdulaziz University.

\section{Study protocol}

The animals were randomly divided into two experimental groups: control (C) and diabetic (D) groups (six to eight rats in each group). Diabetes was induced by a single intraperitoneal injection of streptozotocin (STZ, $50 \mathrm{mg} \mathrm{kg}^{-1}$ ). Glucose levels in tail blood were determined using a glucose meter (ACCU-CHEK; Hoffman-La Roche Ltd., Basel, Switzerland) with noble metal electrode strips. Diabetes was confirmed by a stable hyperglycemia (blood glucose levels of 250-350 $\mathrm{mg} \mathrm{dL}^{-1}$ ) after 2 weeks of STZ injection. The rats were left for an additional 8 weeks to develop vascular complications, based on the results of a recent work from our laboratories. ${ }^{18}$ The animals were then killed by decapitation with rodent guillotine, and the descending thoracic aorta was carefully excised and placed in cold Krebs-Henseleit buffer with the following composition (mM): $\mathrm{NaCl} 118.1, \mathrm{KCl} 4.69, \mathrm{KH}_{2} \mathrm{PO}_{4} 1.2, \mathrm{NaHCO}_{3}$ 25.0, glucose 11.7, $\mathrm{MgSO}_{4} 0.5$, and $\mathrm{CaCl}_{2}$ 2.5. The aorta was then cleaned of fat and connective tissue and cut into three rings ( $\sim 3 \mathrm{~mm}$ length).

\section{Vascular reactivity}

Vascular reactivity of the isolated thoracic aortae was determined using the isolated artery techniques described in previous publications from our laboratories. ${ }^{19,20}$ Isolated aortae from the diabetic group were incubated with different concentrations of 6-gingerol $(0.3-10 \mu \mathrm{M})$ for 30 minutes before assessing the vasoconstriction and vasodilation responses, whereas the isolated aortae from the control group were incubated in DMSO. For assessing the aortic contractile responsiveness, increases in tension due to cumulative additions of PE ( $1 \mathrm{nM}$ to $10 \mu \mathrm{M})$ were recorded and expressed as milligram tension per milligram tissue wet weight. In order to study the vasodilator responsiveness of the aorta, the aortic rings were first precontracted with maximal concentrations of PE $(10 \mu \mathrm{M})$. Cumulative concentrations of $\mathrm{ACh}(1 \mathrm{nM}$ to $\mu \mathrm{M})$ were then added to the organ bath and the response was recorded as percentage in relation to PE precontraction.

\section{Exposure of aortae to advanced glycation end products}

Aortae isolated from the control animals were incubated with methylglyoxal (MG, $200 \mu \mathrm{M})$ for 60 minutes with or without different concentrations of 6-gingerol $(0.3-3 \mu \mathrm{M})$ before studying the vasoconstriction response to $\mathrm{PE}$ and vasodilation response to $\mathrm{ACh}$ as described in the diabetic aortae experiments. 


\section{Direct vasodilation effect of 6-gingerol}

A set of experiments were carried out to investigate the direct vasorelaxant effect and mechanism of action of 6-gingerol. Cumulative concentrations of 6-gingerol $(0.3-10 \mu \mathrm{M})$ were added to the organ bath containing the isolated aortae precontracted with PE $(10 \mu \mathrm{M})$ and the decrease in tension was recorded.

In other sets of experiments, the nitric oxide synthase inhibitor L-NAME $(100 \mu \mathrm{M})$, guanylate cyclase inhibitor MB $(5 \mu \mathrm{M})$, calcium-activated potassium channel blocker TEA $(10 \mathrm{mM})$, or cyclooxygenase inhibitor INDO $(5 \mu \mathrm{M})$ was added 30 minutes before investigating the direct vasorelaxant effect of 6-gingerol as described earlier. The results of 6-gingerol effects were expressed as $\log M$.

\section{ACh-induced $\mathrm{NO}$ generation}

Intracellular NO generation following $\mathrm{ACh}$ activation of the isolated aorta was investigated using the fluorescence probe DAF-FM diacetate as described in a previous work from our laboratories. ${ }^{18}$ Briefly, the isolated aortae were added to 96-well black plates containing $110 \mu \mathrm{L}$ saline and $2.5 \mu \mathrm{M}$ DAF-FM with or without ACh or 6-gingerol (both at $1 \mathrm{mM}$ ) and incubated for 3 minutes at $37^{\circ} \mathrm{C}$. Then, volumes of $90 \mu \mathrm{L}$ were transferred to new wells, and the fluorescence intensity was measured at an excitation wavelength of $485 \mathrm{~nm}$ and an emission wavelength of $525 \mathrm{~nm}$ using a monochromator SpectraMax ${ }^{\circledR}$ M3 plate reader.

\section{Advanced glycation end product formation}

The effect of 6-gingerol on advanced glycation end product (AGE) formation was assessed according to a previously reported method. ${ }^{21}$ Briefly, $10 \mathrm{mg} \mathrm{mL}{ }^{-1}$ BSA was incubated with $100 \mathrm{mM}$ ribose in $100 \mathrm{mM}$ phosphate-buffered saline $(\mathrm{pH} 7.4)$ containing $0.02 \%$ sodium azide at $37^{\circ} \mathrm{C}$ for 2 weeks in the absence or presence of 6-gingerol $(1-1,000 \mu \mathrm{M})$ and $\mathrm{AG}(1 \mathrm{mM})$. The formation of fluorescent AGE was measured using a monochromator SpectraMax ${ }^{\circledR}$ M3 plate reader. The fluorescence intensity was measured at an excitation wavelength of $355 \mathrm{~nm}$ and an emission wavelength of $460 \mathrm{~nm}$.

\section{Statistical analysis}

Values are expressed as mean \pm standard error of the mean. Statistical analysis was performed by the one- or two-way analysis of variance followed by Dunnett's post hoc test using the statistical software Prism $5^{\circledR}$ (Graphpad Software, Inc., La Jolla, CA, USA).

\section{Results \\ Effect of 6-gingerol on vascular reactivity of diabetic aortae}

Diabetic aortae showed exaggerated vasoconstriction in response to PE $\left(10^{-9}\right.$ to $\left.10^{-5} \mathrm{M}\right)$ compared with control aortae. This enhancement of vasoconstriction was highly significant $(P<0.001)$ at $P E$ concentrations of $3 \times 10^{-7}$ to $10^{-5} \mathrm{M}$ (Figure 1A). Incubation with 6-gingerol $(0.3-10 \mu \mathrm{M})$ for 30 minutes alleviated the exaggerated vasoconstriction of diabetic aortae in a concentration-dependent manner. The inhibition of PE $\left(10^{-5} \mathrm{M}\right)$-induced contraction was highly significant $(P<0.001)$ at $3 \mu \mathrm{M}$ 6-gingerol and was significant $(P<0.05)$ at $10 \mu \mathrm{M}$ 6-gingerol (Figure 1A).

Diabetic aortae showed impaired vasodilation in response to ACh $\left(10^{-9}\right.$ to $\left.10^{-5} \mathrm{M}\right)$ compared with control aortae, which was highly significant $(P<0.001)$ at an ACh concentration of $10^{-5} \mathrm{M}$. In contrast to the effects on PE-induced contraction, there was no significant effect of 6-gingerol $(0.3-10 \mu \mathrm{M})$ on the relaxant effect of $\mathrm{ACh}\left(10^{-9}\right.$ to $10^{-5} \mathrm{M}$; Figure 1B).

\section{Effect of 6-gingerol on vascular reactivity of aortae exposed to AGE}

Incubation of diabetic aortae with MG produced exaggerated vasoconstriction in response to PE compared with control aortae (Figure 2), with an enhanced Emax and shift in $\mathrm{pEC}_{50}$. These differences in contraction were highly significant $(P<0.001)$ at $3 \times 10^{-8}$ and $10^{-7} \mathrm{M}$ PE concentrations (Figure 2A). 6-Gingerol $(3 \mu \mathrm{M})$ showed a significant $(P<0.05)$ alleviation of the exaggerated vasoconstriction in response to $10^{-8}$ and $10^{-5} \mathrm{M} P E$ concentrations (Figure 2A). MG produced significant $(P<0.01)$ impairment in aortic vasodilation induced by ACh $\left(3 \times 10^{-6}\right.$ and $\left.10^{-5} \mathrm{M}\right)$ in the diabetic aortae compared to that in the control aortae, while there was no significant effect of $0.3-10 \mu \mathrm{M}$ 6-gingerol (Figure 2B).

\section{Direct vasorelaxant effect of 6-gingerol}

Addition of cumulative concentrations of 6-gingerol $\left(3 \times 10^{-5}\right.$ to $\left.10^{-3} \mathrm{M}\right)$ to the organ bath resulted in a concentrationdependent vasodilation in the isolated diabetic aortae precontracted with $P E$ that was statistically significant $(P<0.001)$ at 6-gingerol concentrations of $3 \times 10^{-4}$ and $10^{-3} \mathrm{M}$. Preincubation with L-NAME or MB (at 100 and $5 \mu \mathrm{M}$ ) for 30 minutes before the cumulative addition of 6-gingerol significantly inhibited the vasodilation effect of 6-gingerol (both at $P<0.001$ ). In contrast, preincubation with TEA 
A

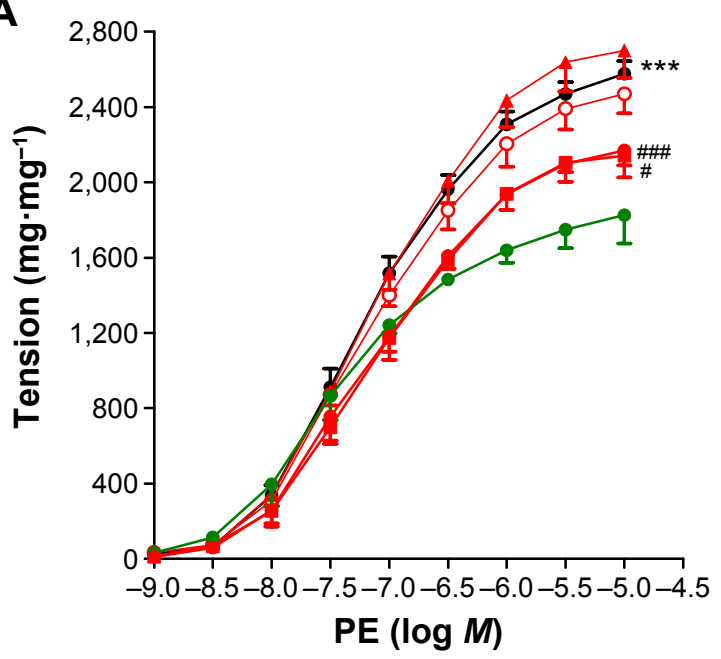

B

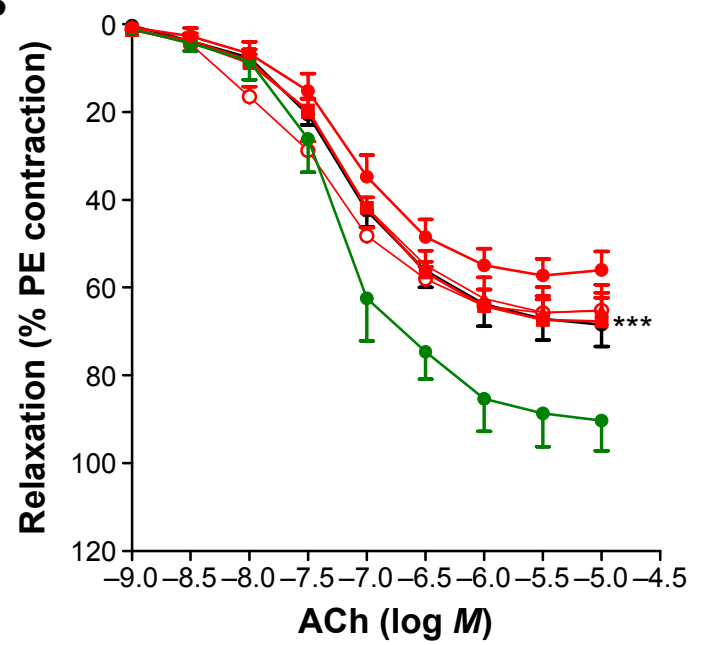

$\rightarrow \mathrm{C} \rightarrow \mathrm{D} \rightarrow 0.3 \mu \mathrm{M}$ 6-gingerol $\leftarrow 1 \mu \mathrm{M}$ 6-gingerol $\rightarrow 3 \mu \mathrm{M}$ 6-gingerol $\rightarrow 10 \mu \mathrm{M}$ 6-gingerol

Figure I Effect of in vitro incubation with different concentrations of 6-gingerol on the responsivess of isolated aorta to PE (A) and ACh (B) in STZ-induced diabetes (D). Notes: Values shown are mean \pm SEM, $n=8-10$. Note that the responses of the tissues treated with 3 and $10 \mathrm{M}$ gingerol are superimposed. $* * * S i g n i f i c a n t l y(P<0.00 \mathrm{I})$ different from the respective control values. "Significantly $(P<0.05)$ different from the respective diabetic values. ${ }^{\#}$ Significantly $(P<0.00 \mathrm{I})$ different from the respective diabetic values.

Abbreviations: PE, phenylephrine; ACh, acetylcholine; STZ, streptozotocin; SEM, standard error of the mean; C, control.

$(10 \mathrm{mM})$ or INDO $(5 \mu \mathrm{M})$ did not significantly affect the vasodilation effect of 6-gingerol (Figure 3).

\section{Effect of 6-gingerol on NO generation}

Incubation of the isolated diabetic aortae in media containing 6-gingerol $\left(10^{-3} \mathrm{M}\right)$ for 3 minutes produced significant

A

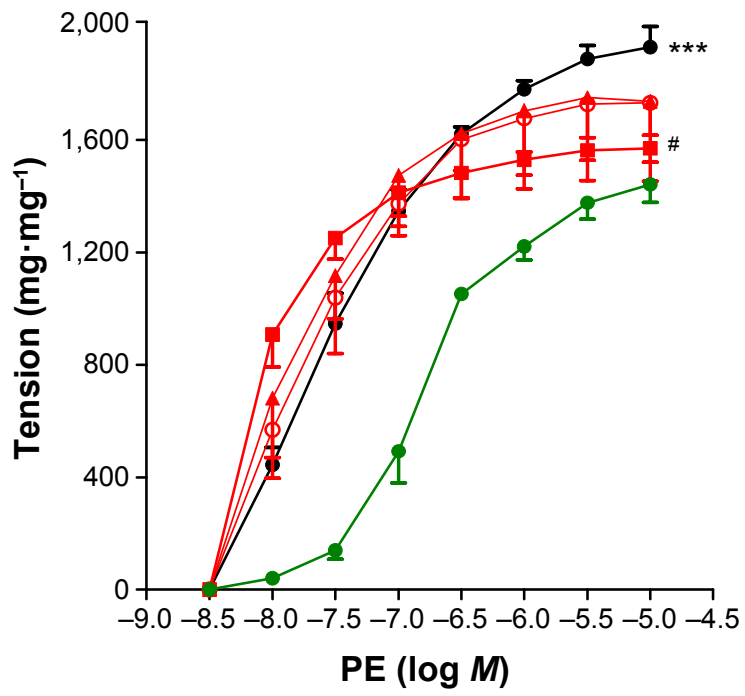

NO generation in a dose-dependent manner (Figure 4A) and to a level similar to that induced by $\mathrm{ACh}\left(10^{-3} \mathrm{M}\right.$; both at $P<0.05$ compared with control; Figure 4B). High drug concentrations were used in these experiments in order to provide an adequate signal-to-noise ratio in the NO assay.

B

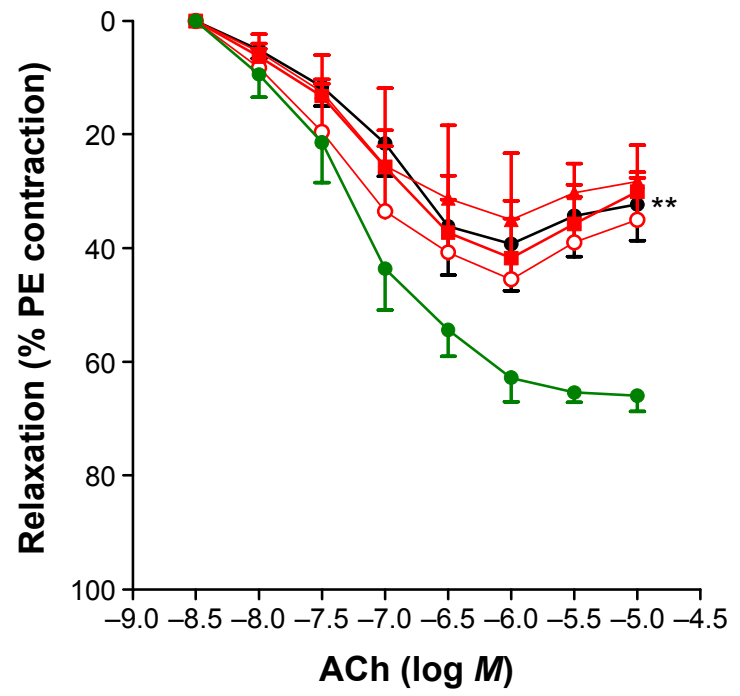

$\rightarrow \mathrm{C} \rightarrow \mathrm{MG} 200 \mu \mathrm{M} \quad-0-3 \mu \mathrm{M}$ 6-gingerol $\rightarrow 1 \mu \mathrm{M}$ 6-gingerol $\rightarrow 3 \mu \mathrm{M}$ 6-gingerol

Figure 2 Effect of 6-gingerol on the responsiveness of isolated aortae to PE (A) and ACh (B) following incubation with methylglyoxal (MG) with increases in the formation of advanced glycation end products (AGEs).

Notes: Values shown are mean \pm SEM, $n=8-10$. **Significantly $(P<0.01)$ different from the respective control values. $* * *$ Significantly $(P<0.00 I)$ different from the respective control values. "Significantly $(P<0.05)$ different from the respective diabetic values.

Abbreviations: PE, phenylephrine; ACh, acetylcholine; SEM, standard error of the mean; C, control. 


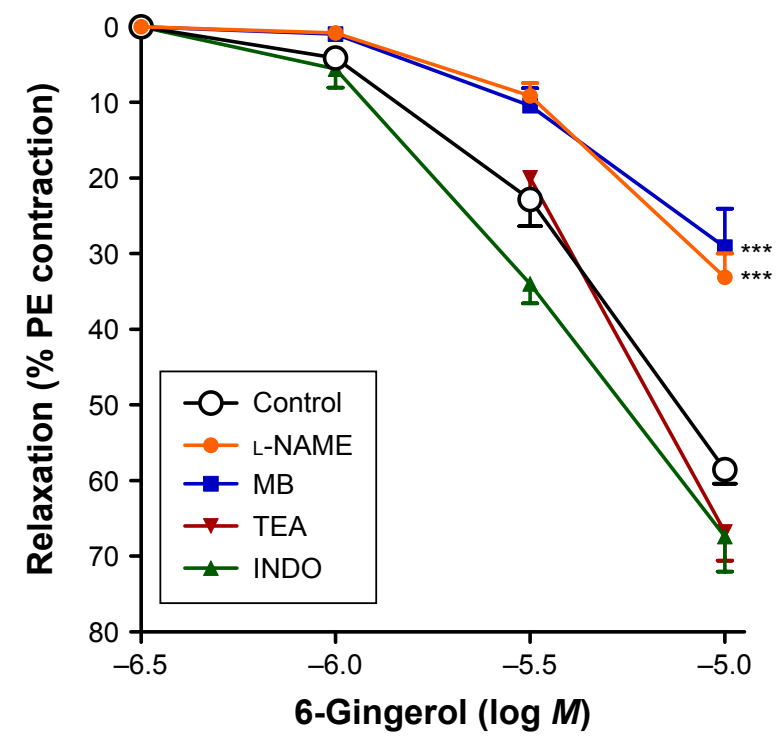

Figure 3 Effect of the nitric oxide synthase inhibitor $\mathrm{N} \omega$-nitro-L-arginine methyl ester hydrochloride (L-NAME, $100 \mu \mathrm{M}$ ), guanylate cyclase inhibitor methylene blue (MB, $5 \mu \mathrm{M})$, calcium-activated potassium channel blocker tetraethylammonium chloride (TEA, $10 \mathrm{mM}$ ), and cyclooxygenase inhibitor indomethacin (INDO, $5 \mu \mathrm{M}$ ) on the direct vasorelaxant effect of 6-gingerol, expressed as log $M$.

Notes: $* * *$ Significantly $(P<0.00 \mathrm{I})$ different from the respective control values. Points show mean \pm SEM of $n=5-8$ tissues.

Abbreviation: SEM, standard error of the mean.

\section{Effect of 6-gingerol on AGE}

Incubation of BSA with ribose increased AGE significantly $(P<0.001)$, as assessed by fluorimetry. This increased level of AGE was significantly $(P<0.001)$ ameliorated when incubated with $\mathrm{AG}(1 \mathrm{mM}$, as positive control), while there was no effect when incubated with different concentrations of 6-gingerol (Figure 5).

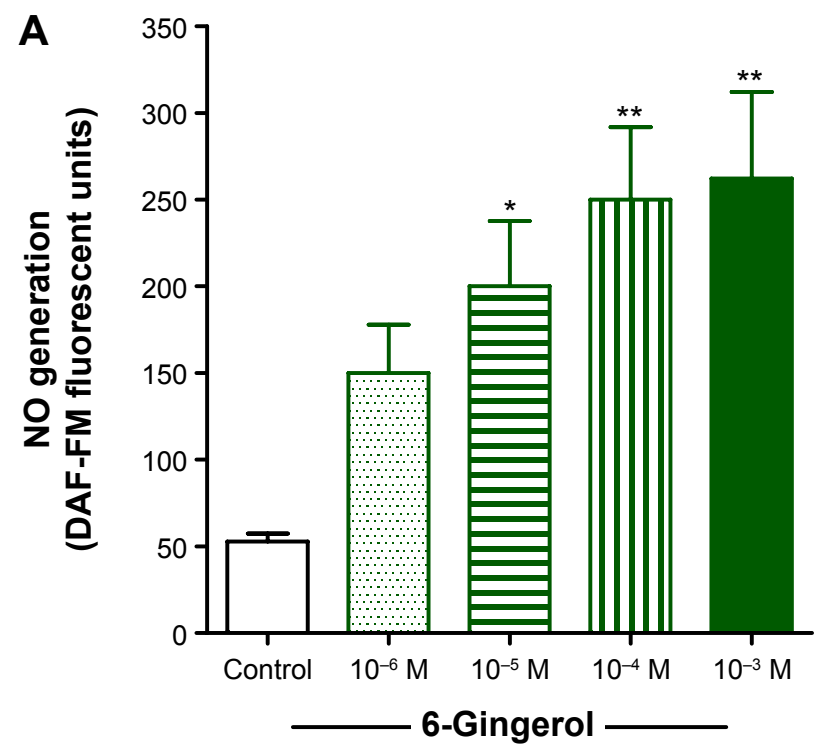

\section{Discussion}

To our knowledge, this is the first study to investigate the vasorelaxant mechanism of 6-gingerol, the main constituent of ginger, in diabetic aortae. The results show that the enhanced $\alpha$-adrenergic responsiveness of aortic rings from diabetic animals was significantly attenuated by 6 -gingerol. This inhibition was concentration dependent with a maximum effect at $3 \mu \mathrm{M}$. The observed alleviation of exaggerated vasoconstriction and the possible mechanism associated with diabetes may be explained based on the following results of the current study: 1) 6-gingerol induced significant relaxation of PE-precontracted aortae, 2) the observed relaxation was significantly inhibited by the NO synthase inhibitor L-NAME and the guanylate cyclase inhibitor $\mathrm{MB}$, and 3) 6-gingerol stimulated $\mathrm{NO}$ generation from the isolated aortae. These findings provide convincing evidence that 6-gingerol offsets the exaggerated vasoconstriction in diabetic aortae through NO-dependent mechanism. The use of 6-gingerol as a complementary medicine in diabetes may help to ameliorate the associated vascular complications.

Increased vascular responsiveness to contractile agents in STZ-diabetic rats has been reported in most of the previous studies, ${ }^{22-24}$ which strongly supports the use of the diabetic model in the current study with regard to vascular abnormalities. Alternatively, some studies reported unchanged ${ }^{25}$ or reduced ${ }^{26}$ vascular response to $\alpha$-adrenergic agonists, which could possibly be explained by the use of low PE concentrations ${ }^{25}$ or the nonspecific adrenergic agonist noradrenaline. ${ }^{26}$

In addition, attenuated relaxation responses to $\mathrm{ACh}$ were observed in the current study in STZ-diabetic aorta, in

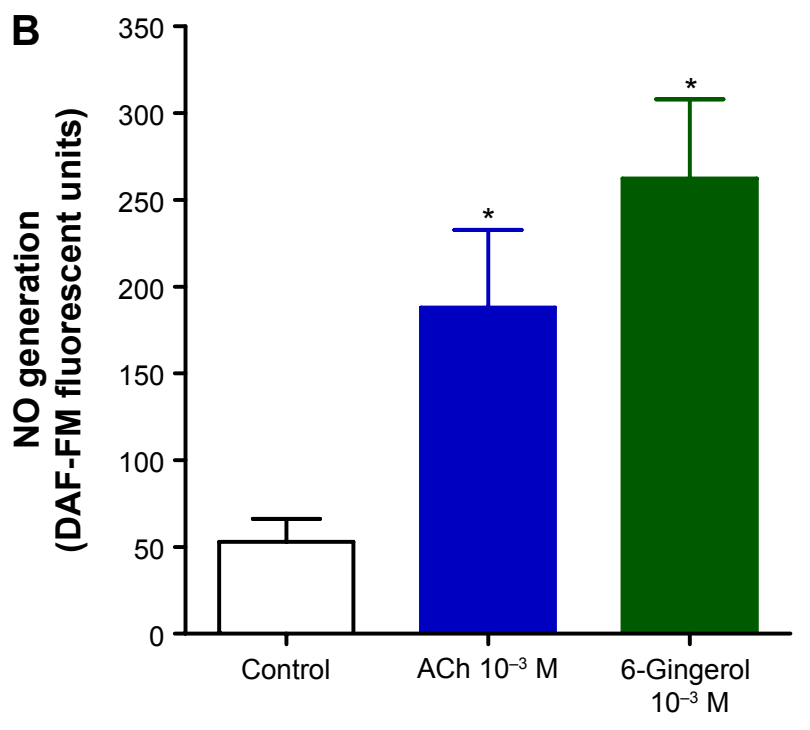

Figure 4 Effect of 6-gingerol $\left(10^{-6}\right.$ to $\left.10^{-3} \mathrm{M}\right)$ on intracellular $\mathrm{NO}$ generation $(\mathbf{A})$ and the effect of the maximum dose compared to acetyl choline (ACh) and control (B). Notes: *Significantly $(P<0.05)$ different from the respective control values. Bars show mean \pm SEM of $n=4-5$ tissues. **Significantly $(P<0.01)$ different from respective control values.

Abbreviations: DAF-FM, 4-amino-5-methylamino-2',7'-difluorofluorescein; SEM, standard error of the mean. 


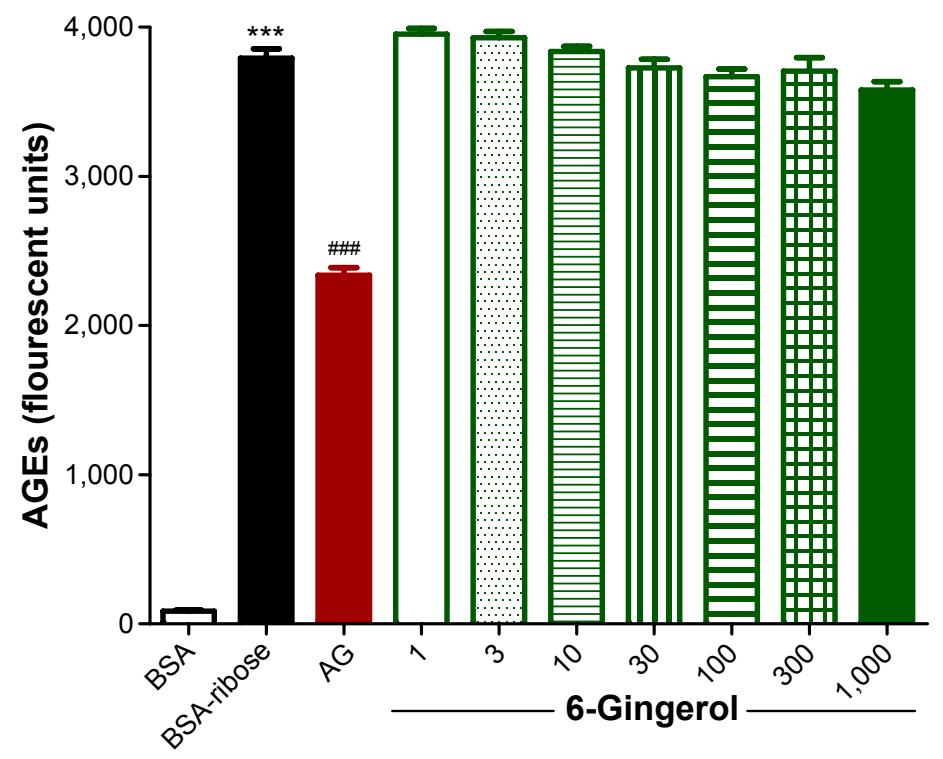

Figure 5 Effect of 6-gingerol $\left(10^{-6}\right.$ to $\left.10^{-3} \mathrm{M}\right)$ on the generation of advanced glycation end products (AGEs).

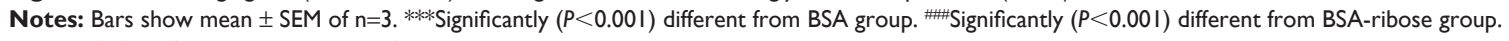
Abbreviation: SEM, standard error of the mean.

agreement with the findings of Orie et al. ${ }^{27}$ In STZ-induced $\mathrm{DM}$, basal levels of NO production and expression of eNOS are reduced in diabetic arteries. ${ }^{28}$ In the present study, the exaggerated vasoconstriction seen in diabetic aortae was significantly attenuated with short-term in vitro incubation with 6-gingerol in a concentration-dependent manner, while the impaired relaxation was not affected.

Because of its pivotal role in the development of cardiovascular complications, ${ }^{29}$ the effect of an AGE metabolite (MG) on vascular contractility and the possible effect of 6-gingerol were investigated. The current study shows that the aortic rings incubated with MG showed an enhanced contractile response to PE similar to diabetic aortae, and this enhanced effect was significantly ameliorated with 6-gingerol. This is in accordance with the reported inhibition of NO availability by AGE in human endothelial cells. ${ }^{30}$ In contrast, the relaxation response to ACh was significantly attenuated when the aortic rings were incubated with MG. This is in accordance with the results of Vlassara et al, ${ }^{31}$ who showed that administration of AGE-modified albumin to nondiabetic rats or rabbits markedly impairs vasodilatory responses to ACh. In the present study, incubation with 6-gingerol significantly alleviated the exaggerated vasoconstriction in the aortae exposed to MG, but did not affect the impaired relaxation.

The mechanism(s) by which 6-gingerol alleviates vasoconstriction of diabetic aortae could be mediated by direct vasodilation through $\mathrm{NO}$ generation and stimulation of GC. In the present study, 6-gingerol induced significant relaxation of PE-precontracted aortae. This is in agreement with the reported antihypertensive effect of ginger aqueous extract and its phenolic constituents in rats. ${ }^{32}$ The observed vasodilation seems to be through stimulating NO generation from the vasculature as it was significantly inhibited by the NOS inhibitor and the GC inhibitor, while not affected by the calciumactivated potassium channel blocker or the cyclooxygenase inhibitor INDO. In support of this, we found that 6-gingerol stimulated similar amounts of $\mathrm{NO}$ generation to those by $\mathrm{ACh}$. In contrast, incubation with 6-gingerol did not affect AGE formation. This suggests that the observed alleviation of exaggerated vasoconstriction by 6-gingerol due to $\mathrm{MG}$ incubation is through inhibiting the effects of AGE on the blood vessels rather than affecting AGE formation. This is consistent with the reported decrease in the soluble receptor for AGE induced by 6 -gingerol in doxorubicin-treated rats. ${ }^{33}$

\section{Conclusion}

The current study showed that 6-gingerol ameliorates enhanced vascular contraction in diabetic aortae, which may be partially attributed to the vasodilation effect of 6-gingerol through stimulation of aortic $\mathrm{NO}$ generation.

\section{Acknowledgments}

The authors would like to thank Mr Islam Farouk, Department of Pharmacology and Toxicology, Faculty of Pharmacy, King Abdulaziz University, Jeddah, Saudi Arabia, for his effort and help in the experimental study. This project was funded by the National Plan for Science, Technology and Innovation (MAARIFAH) - King Abdulaziz City for Science and 
Technology-Saudi Arabia-award number(12-MED-3063-03). The authors also acknowledge Science and Technology Unit, King Abdulaziz University for technical support.

\section{Author contributions}

Salah A Ghareib, Hany M El-Bassossy, Ahmed A Elberry, and Malcolm L Watson participated in research design. Salah A Ghareib, Hany M El-Bassossy, and Ahmad A Elberry conducted experiments. Hany M El-Bassossy, Ahmad Azhar, and Zainy M Banjar performed data analysis. Hany M El-Bassossy, Ahmed A Elberry, and Malcolm L Watson wrote or contributed to the writing of the manuscript. All authors contributed toward data analysis, drafting and critically revising the paper and agree to be accountable for all aspects of the work.

\section{Disclosure}

The authors report no conflicts of interest in this work.

\section{References}

1. International Diabetes Federation 2014 http://www.idf.org/ worlddiabetesday/toolkit/gp/facts-figures. Accessed, 10 August 2015.

2. de Ferranti SD, de Boer IH, Fonseca V, et al. Type 1 diabetes mellitus and cardiovascular disease: a scientific statement from the American Heart Association and American Diabetes Association. Circulation. 2014; 130:1110-1130.

3. Pambianco G, Costacou T, Ellis D, Becker DJ, Klein R, Orchard TJ. The 30-year natural history of type 1 diabetes complications: the Pittsburgh Epidemiology of Diabetes Complications Study Experience. Diabetes. 2006;55:1463-1469.

4. Nichols GA, Hillier TA, Erbey JR, Brown JB. Congestive heart failure in type 2 diabetes: prevalence, incidence and risk factors. Diabetes Care. 2001; 24:1614-1619.

5. Janghorbani M, Rexrode KM, Logroscino G. Prospective study of type 1 and type 2 diabetes and risk of stroke subtypes: the Nurses' Health Study. Diabetes Care. 2007;30:1730-1735.

6. Bjornstad P, Cherney D, Maahs DM. Early diabetic nephropathy in type 1 diabetes - new insights. Curr Opin Endocrinol Diabetes Obes. 2014;21: 279-286.

7. Fong DS, Aiello L, Gardner TW, et al. Diabetic retinopathy. Diabetes Care. 2003;26:226-229.

8. Williams SB, Cusco JA, Roddy MA, Johnstone MT, Creager MA. Impaired nitric oxide-mediated vasodilation in patients with non-insulindependent diabetes mellitus. J Am Coll Cardiol. 1996;27:567-574.

9. Nugent AG, McGurk C, Hayes JR, Johnston GD. Impaired vasoconstriction to endothelin 1 in patients with NIDDM. Diabetes. 1996;45: 105-107.

10. Badreldin HA, Gerald B, Musbah OT, Abderrahim N. Some phytochemical, pharmacological and toxicological properties of ginger (Zingiber officinale Roscoe): a review of recent research. Food Chem Toxicol. 2008;46:409-420.

11. Duke JA. Handbook of Medicinal Herbs. Boca Raton, FL: CRC Press; 2002:327-329.

12. Langner E, Greifenberg S, Gruenwald J. Ginger: history and use. $A d v$ Ther. 1998;15:25-44.

13. Dugasani S, Pichika MR, Nadarajah VD, Balijepalli MK, Tandra S, Korlakunta JN. Comparative antioxidant and anti-inflammatory effects of [6]-gingerol, [8]-gingerol, [10]-gingerol and [6]-shogaol. J Ethnopharmacol. 2010;127:515-520.
14. Chakraborty D, Mukherjee A, Sikdar S, Paul A, Ghosh S, KhudaBukhsh AR. [6]-Gingerol isolated from ginger attenuates sodium arsenite induced oxidative stress and plays a corrective role in improving insulin signaling in mice. Toxicol Lett. 2012;210:34-43.

15. Kim EC, Min JK, Kim TY, et al. [6]-Gingerol, a pungent ingredient of ginger, inhibits angiogenesis in vitro and in vivo. Biochem Biophys Res Commun. 2005;335:300-308.

16. Lee HS, Seo EY, Kang NE, Kim WK. [6]-Gingerol inhibits metastasis of MDA-MB-231 human breast cancer cells. J Nutr Biochem. 2008;19: 313-319.

17. Liao YR, Leu YL, Chan YY, Kuo PC, Wu TS. Anti-platelet aggregation and vasorelaxing effects of the constituents of the rhizomes of Zingiber officinale. Molecules. 2012;17(8):8928-8937.

18. El-Bassossy HM, El-Fawal R, Fahmy A. Arginase inhibition alleviates hypertension associated with diabetes: effect on endothelial dependent relaxation and NO production. Vascul Pharmacol. 2012;57:194-200.

19. El-Bassossy HM, El-Moselhy MA, Mahmoud MF. Pentoxifylline alleviates vascular impairment in insulin resistance via TNF- $\alpha$ inhibition. Naunyn Schmiedebergs Arch Pharmacol. 2011;384:277-285.

20. Mahmoud MF, Hassan NA, El Bassossy HM, Fahmy A. Quercetin protects against diabetes-induced exaggerated vasoconstriction in rats: effect on low grade inflammation. PLoS One. 2013;8:e63784.

21. Adisakwattana S, Jiphimai P, Prutanopajai P, Chanathong B, Sapwarobol S, Ariyapitipan T. Evaluation of $\alpha$-glucosidase, $\alpha$-amylase and protein glycation inhibitory activities of edible plants. Int J Food Sci Nutr. 2010;61:295-305.

22. Abebe W, Harris KH, Macleod KM. Enhanced contractile responses of arteries from diabetic rats to $\alpha 1$-adrenoceptor stimulation in the absence and presence of extracellular calcium. J Cardiovasc Pharmacol. 1990;16:239-248.

23. Ozcelikay AT, Pekiner C, Ari N, Ozturk Y, Ozuari A, Altan VM. The effect of vanadyl treatment on vascular responsiveness of streptozotocin-diabetic rats. Diabetologia. 1994;37:572-578.

24. Zhu BH, Guan YY, Min J, He H. Contractile responses of diabetic rat aorta to phenylephrine at different stages of diabetic duration. Acta Pharmacol Sin. 2001;22:445-449.

25. Buñag RD, Tomita T, Krizsan D. Renovascular beta adrenergic hypersensitivity and hyperinsulinemia in rats with dietary-induced obesity. J Pharmacol Exp Ther. 1990;255(1):325-332.

26. Leung JYT, Kwok EWY, Liu GY, Pang CCY. Attenuated $\alpha$-adrenoceptormediated arterial and venous constrictions in rat models of diabetes. Eur J Pharmacol. 2010;642(1-3):128-133.

27. Orie NN, Aloamaka CP, Iyawe VI. Duration-dependent attenuation of acetylcholine-but not histamine-induced relaxation of the aorta in diabetes mellitus. Gen Pharmacol. 1993;24:329-332.

28. Leo CH, Hart JL, Woodman OL. Impairment of both nitric oxide-mediated and EDHF type relaxation in small mesenteric arteries from rats with streptozotocin-induced diabetes. Br J Pharmacol. 2011;162:365-377.

29. Mukohda M, Okada M, Hara Y, Yamawaki H. Exploring mechanisms of diabetes-related macrovascular complications: role of methylglyoxal, a metabolite of glucose on regulation of vascular contractility. J Pharmacol Sci. 2012;118:303-310.

30. Xu B, Ji Y, Yao K, Cao YX, Ferro A. Inhibition of human endothelial cell nitric oxide synthesis by advanced glycation end-products but not glucose: relevance to diabetes. Clin Sci (Lond). 2005;109(5):439-446.

31. Vlassara H, Fuh H, Makita Z, Krungkrai S, Cerami A, Bucala R. Exogenous advanced glycosylation end products induce complex vascular dysfunction in normal animals: a model for diabetic and aging complications. Proc Natl Acad Sci U S A. 1992;89:12043-12047.

32. Ghayur MN, Gilani AH, Afridi MB, Houghton PJ. Cardiovascular effects of ginger aqueous extract and its phenolic constituents are mediated through multiple pathways. Vascul Pharmacol. 2005;43(4): 234-241.

33. El-Bakly WM, Louka ML, El-Halawany AM, Schaalan MF. 6-Gingerol ameliorated doxorubicin-induced cardiotoxicity: role of nuclear factor kappa B and protein glycation. Cancer Chemother Pharmacol. 2012; 70(6):833-841. 


\section{Publish your work in this journal}

Drug Design, Development and Therapy is an international, peerreviewed open-access journal that spans the spectrum of drug design and development through to clinical applications. Clinical outcomes, patient safety, and programs for the development and effective, safe, and sustained use of medicines are a feature of the journal, which

has also been accepted for indexing on PubMed Central. The manuscript management system is completely online and includes a very quick and fair peer-review system, which is all easy to use. Visit http://www.dovepress.com/testimonials.php to read real quotes from published authors.

Submit your manuscript here: http://www.dovepress.com/drug-design-development-and-therapy-journal 